\title{
Effects of Feelings of Inadequacy on Life Events, Social Avoidance and Distress Among Impoverished Undergraduates
}

\author{
Shengyu Zhao ${ }^{1}$, Jibo Ye ${ }^{2, *}$ \\ ${ }^{1}$ Department of Common Education, Wenzhou Vocational and Technical College, Wenzhou, China \\ ${ }^{2}$ College of Extend Education, Wenzhou Vocational and Technical College, Wenzhou, China \\ Email address: \\ 64088876@qq.com (Shengyu Zhao),54876745@qq.com (Jibo Ye) \\ ${ }^{*}$ Corresponding author
}

To cite this article:

Shengyu Zhao, Jibo Ye. Effects of Feelings of Inadequacy on Life Events, Social Avoidance and Distress Among Impoverished Undergraduates. American Journal of Applied Psychology. Vol. 8, No. 1, 2019, pp. 19-26. doi: 10.11648/j.ajap.20190801.14

Received: March 6, 2019; Accepted: April 22, 2019; Published: May 29, 2019

\begin{abstract}
The aim of this study is to understand the relationship between life events, social avoidance and distress as well as the feelings of inadequacy among impoverished undergraduates. 766 impoverished undergraduate participants undertook Adolescent Self-Rating Life Events Scale (ASLEC), Social Avoidance and Distress Scale (SADS) and Feeling of Inadequacy Scale (FIS) in this study. Findings revealed that (1) Life events, social avoidance and distress as well as the feelings of inadequacy were significantly correlated, (2) feelings of inadequacy has a complete mediating effect on life events as well as social avoidance and distress. Life events show no direct causation of social avoidance and distress. Rather, it is through the feelings of inadequacy that can significantly predict the effects of life events on social avoidance and distress among impoverished undergraduates.
\end{abstract}

Keywords: Impoverished Undergraduates, Life Events, Social Avoidance and Distress, Feelings of Inadequacy, Mediation Effect

\section{Introduction}

The viability and developmental issues among impoverished tertiary students have been highly discussed by society. Research conducted on the poor and underprivileged have revealed that difficulties in family finances jeopardizes one's wellbeing, self-development and interpersonal relationships, which in turn causes more developmental challenges [1-2]. As a special group among tertiary students, impoverished students are under constant stress from demands like finances, livelihood and academics where they face more challenges - with the detection rate of psychological problems at $33.72 \%$ [3]. Studies conducted by Cheng and Zhang, Fang $\&$ Miao et al. have shown that psychological health among impoverished undergraduates is significantly lower than an average undergraduate [4-5]. In comparison to an average undergraduate, an impoverished undergraduate's daily life, academic and career pursuits as well as self-concept are much more easily influenced and affected by negative life events [6].
Life events are common psychosocial stressors - referred as the various occurrences in an individual's life that require the individual to respond with change and adaptation. Individual experiences can be categorized into negative and positive experiences, where both largely influence the wellbeing of the individual. A study conducted by Garnefski and Kraaij showed that negative life events can easily trigger negative emotions such as unease, distress and anxiety in an individual [7] and Hojat et al. showed that life events among impoverished undergraduates can effectively predict anxiety levels [8]. Impoverished undergraduates can't help but avoid socializing due to the fact that they live in a much harsher and demanding societal environment [9]. As such, impoverished undergraduates are more proned to experience lower levels of pleasure from socializing, and are more proned to avoidant communication behaviour and experience distress in communication with others [10].

When it comes to the relationship between life experiences and self-development - the mechanism where life events 
predicts mental and physical wellbeing-some think that negative life events has a direct causation of psychological issues [11] whereas some think that life events have a mediating effect on an individual's self-evaluation [10], coping mechanisms [12], resilience [13], etc. Among the many mediating variables, self-concept and self-evaluation have a highly deciding influence on the individual's psychological wellbeing. Self-evaluation refers to self-awareness and self-understanding - the core concept of the existence of self and self-value in an individual's personality, where one understands, evaluates and determines his or her biopsychosocial characteristics [14]. Individuals who display high self-appraisal often display a strong sense of self-esteem, dignity, self-respect, self-approval and self-acceptance where they would therefore seek acknowledgement from others, their community and the society. On the other hand, low self-appraisal can easily cause an individual to develop feelings of inferiority, resignation and self-denial, which have negative effects on the individual's mental health [15].

Due to the limitations of family financial conditions, impoverished students have an individualistic sense of self-understanding, self-evaluation and self-experience, where they commonly feel a sense of inadequacy when it comes to themselves against their living situation [10]. As such, do life events have a direct influence on the social avoidance and distress in impoverished students or is their distress under the influence of self-evaluation factor (feelings of inadequacy)? Many tertiary schools offer financial aid services for impoverished undergraduates, but do these aids effectively decrease the effects of life events as a stressor and in turn improve the students' social situations? How can the social situation of impoverished students be improved through social and emotional support, as well as financial aid? How can School Mental Health programmes adapt to the psychosocial needs of impoverished student groups? How can we, then effectively resolve psychological and behavior issues that can be present in the social settings of these students? These are issues that should be further studied.

Objective of Study

This study will reveal how life events and feelings of inadequacy affect impoverished undergraduates' social avoidance and social distress through structural equation model, providing a foundation for further studies on mental health of impoverished undergraduates. We therefore hypothesized that 1) there will be a significant difference among different groups of impoverished undergraduates (in terms of sex, grade and only children or not) in of life events, feelings of inadequacy, social avoidance and social distress; 2) there will be a significant correlation among social avoidance and distress, life events, and feelings of inadequacy; 3) life events will predict social avoidance and distress directly while feelings of inadequacy will play a mediating role between them.

\section{Methodology}

\subsection{Participants}

The current study recruited and surveyed participants from three universities located at Zhejiang, Wenzhou through cluster random sampling. Low-income participants were sampled through the college's student affairs department which holds financial information of the undergraduates. A total of 800 sets of survey were distributed and 790 sets were eventually collected. After the exclusion of invalid surveys, the final number of questionnaire collected was 766 sets, with a response rate of $95.75 \%$. The composition of the participants is as followed: 316 males (41.3\%), 450 females $(58.7 \%) ; 242$ only child $(31.6 \%), 524$ have siblings $(68.4 \%)$; 131 from rural regions $(17.1 \%), 635$ from urban regions $(82.9 \%) ; 315$ were freshmen $(41.1 \%), 215$ were sophomores $(28.1 \%), 201$ were juniors $(26.2 \%)$ and 35 were seniors (4.6\%).

\subsection{Measures}

\subsubsection{Adolescent Self-Rating Life Events Scale (ASLEC)}

ASLEC lists 27 common stressors that adolescents experience in life, it us used to determine the frequency and severity of stress of life events. The scale includes six major factors such as interpersonal relationships, academic stress, punishment, loss, health adjustment and other stressors. ASLEC adopts a five-point likert scale $(1=$ not severe at all, $2=$ slightly severe, $3=$ moderately severe, $4=$ very severe, $5=$ extremely severe), the higher the scores would mean the more stressfulness the participant perceive about life events [16]. The current study's alpha is at 0.909 (Cronbach's $\alpha=$ $0.85)$.

\subsubsection{Social Avoidance and Distress Scale (SADS)}

Authored by Watson and Friend (1969), SADS measures two aspects of social anxiety - Social Avoidance and Social Distress. A five-point likert scale based on 28 social interaction and experience items were administered $(1=$ not at all, 5 = extremely), the higher the scores meant the more severe the social avoidance and distress experienced. The correlation coefficient mean of the current scale items to the total mean is at 0.77 [16] (Cronbach's $\alpha=0.879$ ).

\subsubsection{The Feelings of Inadequacy Scale (FIS)}

Modified and revised by Fleming, FIS includes 36 biopsychosocial related items that measures the feelings of inadequacy, inferiority, sensitivity and social anxiety based on the individual's self-esteem, social confidence, academic capabilities, appearance, physical abilities. A seven-point likert scale is used in the questionnaire, where the higher the score of feelings of inadequacy, the lower self-value and self-evaluation an individual would experience [16]. The current study's $\alpha=0.917$ (Cronbach's $\alpha=0.92$ ).

\subsection{Ethical Considerations}

Since all subjects in this study are above the age of 18 years, we obtained informed consent from them after we have explained to them the purpose and method of this study. In 
addition, we assured the subjects that their responses will be confidential and that their identities will not be revealed.

\subsection{Data Analysis}

SPSS 20.0 and Amos 20.0 were used for data consolidation and analysis.

\section{Results}

\subsection{Overall Analysis and Groups Differences in Life Events, Feelings of Inadequacy and Social Avoidance and Distress}

In the current study, the ASLEC mean score distribution is at $1.72 \pm 0.51$. The factors are ranked from the highest score to the lowest as followed: Academic stress (1.99 \pm 0.64$)$,

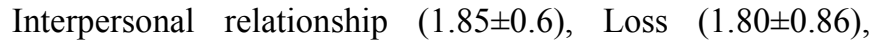
Health adjustment $(1.62 \pm 0.51)$, Other stressors $(1.57 \pm 0.61)$ and Punishment $(1.52 \pm 0.61)$. In the FIS survey, the mean score distribution in impoverished students is at $3.39 \pm 0.83$, with the factors ranked from the highest score to the lowest as followed: Appearance (3.70 \pm 1.03$)$, Physical abilities (3.46 \pm 1.34$)$, Social confidence $(3.44 \pm 1.06)$, Academic

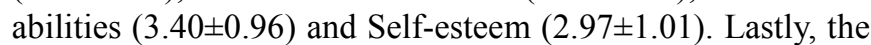
score distribution for the SADS is at $78.53 \pm 13$, with Social avoidance at $39.29 \pm 6.81$, and Social distress at 39.25 \pm 7.45 .

Based on the analysis of the different demographics of participants, feelings of inadequacy have significant gender differences $(t=-2.331, p=0.020)$; life events scores have significant differences among the different academic levels $(F=2.686, p=0.046)$; and only child participants have a higher SADS score than non-only child participants $(t=2.462$, $p=0.014)$.

\subsection{Correlation Between Life Events, Feelings of Inadequacy and Social Avoidance and Distress}

Based on the analysis of results, it shows that factors such as life events and feelings of inadequacy have a significant positive correlation with social avoidance and social distress (See Table 1).

Table 1. Correlation between Life events, Feelings of Inadequacy and Social Avoidance and Distress (r).

\begin{tabular}{|c|c|c|c|c|c|c|c|c|c|}
\hline Degree & Self-Esteem & $\begin{array}{l}\text { Social } \\
\text { Confidence }\end{array}$ & $\begin{array}{l}\text { Academic } \\
\text { Abilities }\end{array}$ & Appearance & $\begin{array}{l}\text { Physical } \\
\text { Abilities }\end{array}$ & $\begin{array}{l}\text { Feelings of } \\
\text { Inadequacy } \\
\text { (Mean) }\end{array}$ & $\begin{array}{l}\text { Social } \\
\text { Avoidance }\end{array}$ & $\begin{array}{l}\text { Social } \\
\text { Distress }\end{array}$ & $\begin{array}{l}\text { Social } \\
\text { Avoidance and } \\
\text { Social Distress }\end{array}$ \\
\hline $\begin{array}{l}\text { Interpersonal } \\
\text { Relationships }\end{array}$ & $0.233^{* *}$ & $0.279^{* *}$ & $0.248^{* *}$ & $0.218^{* *}$ & $0.226^{* *}$ & $0.314^{* *}$ & $0.187^{* *}$ & $0.228^{* *}$ & $0.222^{* *}$ \\
\hline Academic Stress & $0.211^{* *}$ & $0.255^{* *}$ & $0.281^{* *}$ & $0.233^{* *}$ & $0.220^{* *}$ & $0.312^{* *}$ & $0.161^{* *}$ & $0.194^{* *}$ & $0.190^{* *}$ \\
\hline Punishment & $0.186^{* *}$ & $0.140^{* *}$ & $0.208^{* *}$ & $0.141^{* *}$ & $0.092^{*}$ & $0.195^{* *}$ & $0.163^{* *}$ & $0.215^{* *}$ & $0.203^{* *}$ \\
\hline Loss & $0.129^{* *}$ & $0.149^{* *}$ & $0.170^{* *}$ & $0.169^{* *}$ & $0.157^{* *}$ & $0.203^{* *}$ & $0.120^{* *}$ & $0.118^{* *}$ & $0.127^{* *}$ \\
\hline Health Adjustment & $0.237^{* *}$ & $0.157^{* *}$ & $0.187^{* *}$ & $0.150^{* *}$ & $0.122^{* *}$ & $0.219^{* *}$ & $0.137^{* *}$ & $0.143^{* *}$ & $0.149^{* *}$ \\
\hline Other Stressors & $0.227^{* *}$ & $0.151^{* *}$ & $0.202^{* *}$ & $0.146^{* *}$ & $0.082^{*}$ & $0.204^{* *}$ & $0.175^{* *}$ & $0.190^{* *}$ & $0.194^{* *}$ \\
\hline Life Events (Mean) & $0.253^{* *}$ & $0.239^{* *}$ & $0.273^{* *}$ & $0.226^{* *}$ & $0.194^{* *}$ & $0.306^{* *}$ & $0.198^{* *}$ & $0.228^{* *}$ & $0.227^{* *}$ \\
\hline Social Avoidance & $0.431^{* *}$ & $0.433^{* *}$ & $0.349^{* *}$ & $0.298^{* *}$ & $0.291^{* *}$ & $0.467^{* *}$ & - & - & $0.933^{* *}$ \\
\hline Social Distress & $0.423^{* *}$ & $0.508^{* *}$ & $0.390^{* *}$ & $0.332^{* *}$ & $0.330^{* *}$ & $0.514^{* *}$ & - & - & $0.944^{* *}$ \\
\hline $\begin{array}{l}\text { Social Avoidance } \\
\text { and Distress }\end{array}$ & $0.454^{* *}$ & $0.503^{* *}$ & $0.394^{* *}$ & $0.336^{* *}$ & $0.331^{* *}$ & $0.524^{* *}$ & - & - & - \\
\hline
\end{tabular}

Note: $* p<0.05, * *<0.01$.

\subsection{Path Analysis of Life Events, Feelings of Inadequacy and Social Avoidance and Distress in Impoverished Undergraduates}

Regression analysis have shown that certain factors of life events and feelings of inadequacy have a predicting effect on impoverished undergraduates' social avoidance and distress and how life events, feelings of inadequacy as well as social avoidance and distress influence each other requires validation through a structural equation model. The current study hypothesizes that feelings of inadequacy has a significant mediating effect on life events' influence on impoverished undergraduate's social avoidance and distress levels. According to Baron and Kenny's [17] Mediation Analysis, the structural equation model is structured for examination under the following conditions: (1) Half the sample ( $n=338)$ is used in the path model (Figure 1); (2) Revision made to the path model which the modified path model is derived (Figure 2), with the fitting indices matching the requirements of the survey; (3) The other half of the sample $(n=338)$ is used for the validation of the modified path model, to achieve the final overall model (See Table 2).

Table 2. Goodness of Fit Index of the Mediating Effect of Feelings of Inadequacy.

\begin{tabular}{|c|c|c|c|c|c|c|c|c|c|}
\hline Model & $\chi^{2}$ & $d f$ & $\chi^{2} / d f$ & RMSEA & GFI & $A G F I$ & NFI & CFI & $I F I$ \\
\hline Explored & 171.439 & 62 & 2.765 & 0.068 & 0.930 & 0.897 & 0.933 & 0.956 & 0.956 \\
\hline Modified & 102.597 & 60 & 1.710 & 0.043 & 0.958 & 0.936 & 0.960 & 0.983 & 0.983 \\
\hline Verified & 139.942 & 60 & 2.332 & 0.059 & 0.945 & 0.916 & 0.937 & 0.963 & 0.962 \\
\hline
\end{tabular}




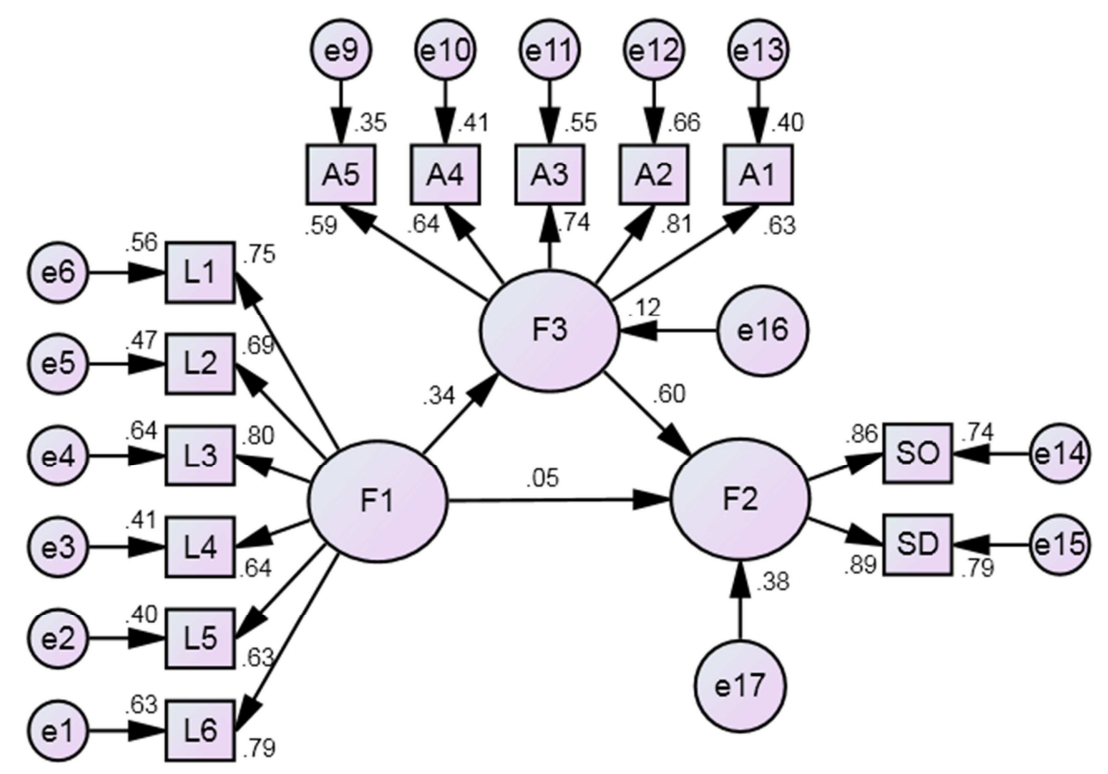

Figure 1. Explored Path Model.

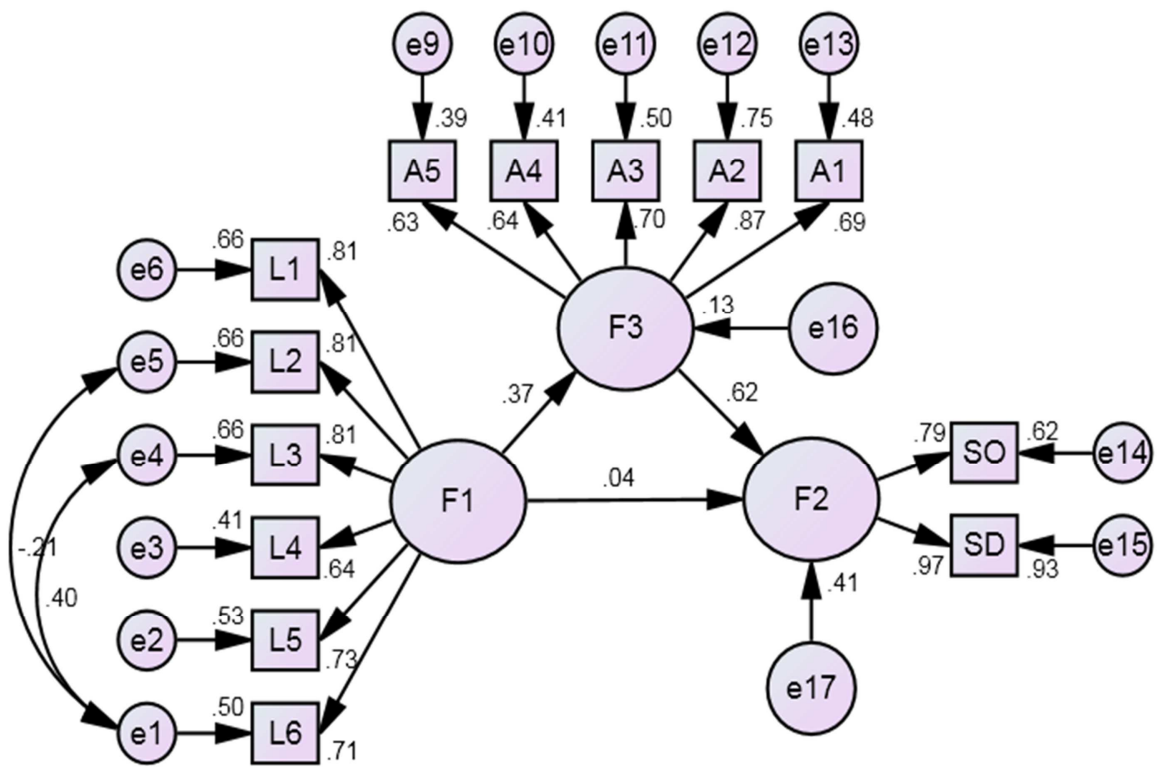

Figure 2. Modified Path Model.

Note: F1: Life Events, F2: Social Avoidance and Distress, F3: Feelings of Inadequacy; SO: Social Avoidance, SD: Social Distress; L1: Interpersonal Relationships. L2: Academic Stress, L3: Punishment, L4: Loss, L5: Health Adjustment, L6: Other Stressors; A1: Self-esteem, A2: Social Confidence, A3: Academic Ability, A4: Appearance, A5: Physical Ability

Based on the modified model, the direct prediction score of life events on social avoidance and distress is $0.04(p>0.05)$, while life events' influences on feelings of inadequacy indirectly predicts social avoidance and distress with the indirect prediction score of 0.23 , with indirect prediction being $85.19 \%$ of the overall effect. From the Modified Path Model, it is observed that the direct prediction score is 0.03 and the indirect prediction score is 0.23 , with indirect effect accounting for $88.46 \%$ of the overall effect. Individual item score in the Path Model is not much different from the modified path model, which therefore proposes that the modified path model is acceptable. The SEM have shown that feelings of inadequacy has a significant mediating effect on life events and social avoidance and distress, which means that life events have no direct causation of social avoidance and distress. Instead, it is through the effects of feelings of inadequacy that social behaviour and social experiences are indirectly affected by life events.

\section{Discussion}

\subsection{Overall Analysis of Life Events, Feelings of Inadequacy Social Avoidance and Distress in Impoverished Undergraduates}

In a fast-growing economy and society, poverty and the lack 
of material goods have negative effects on an individual's life, self-evaluation and social standing. From the study results, it can be observed that the main life stressors that impoverished tertiary students experience the most are academic stress, interpersonal relationships and loss. It shows that impoverished students often feel inferior because of their lacking family financial background. They feel a strong sense of loss yet at the same time have an intense need for some form of self-esteem, which therefore motivate a great desire to change their fate and family financial circumstances [18]. Impoverished tertiary students experience above average levels of feelings of inadequacy, especially in areas such as appearances, physical abilities and social confidence. The results showed that impoverished tertiary students experience higher sense of inadequacy, and a lower sense of self-esteem which can lead to a higher possibility of various psychological problems. In addition, impoverished tertiary students experience moderate levels of social avoidance and distress, which is supported by research done in the country [19].

Statistical differences in groups revealed that there were significant gender differences in the feelings of inadequacy in impoverished students, with female students experiencing more feelings of inadequacy compared to male students. These results corresponded with Xue-fen Shen and Can-hua Dong's research [20]. Under normal circumstances, men are regarded in a higher societal position where they are viewed as more career-driven whereas on the other hand, women are regarded as the lesser gender and therefore are placed lower in social value and positioning. Other than gender differences, academic levels also play a significant role on life events in tertiary students, with the seniors and fourth years more concerned about the job market, career path and graduation pathways, etc.

\subsection{Correlation Analysis Between Life Events, Feelings of Inadequacy Social Avoidance and Distress in Impoverished Undergraduates}

Relevant analyses have shown that life events, social avoidance and distress as well as feelings of inadequacy has a significant positive correlation among impoverished tertiary students, which is supported by the study conducted by Huang, Zhang \& Huang [21], Guo [22] and others. Generally, negative life events affect an individual's socialization and self-esteem [16]. Research conducted by Situ [23], Wang, Tang, Li [24] and Zhong \& Zhang [25] have also discovered the relationship between social anxiety and low self-esteem [18-21]. Negative life events can be categorized as major family events and unfortunate events as well as small incidents that happened in the family, school and daily life such as the loss of loved ones, financial difficulties, poor image, interpersonal sensitivity and inferiority, etc - which can create a negative effect on an individual's self-understanding and lead to pessimistic coping behavior [16]. When negative events occur as a collective event, it can easily turn into a "multiple-effect" which may exceed the effects of a singular crisis or critical event on the individual [26]. Research have also discovered that there is a significant positive correlation level between feelings of inadequacy and social avoidance and distress $(r=0.524)$, therefore, the higher the score on the Feelings of Inadequacy score, the higher the score on the Social Avoidance and Distress Scale. Particularly, self-esteem and social avoidance and distress are moderately correlated. Social inadequacy, on the other hand, is negatively correlated to social avoidance and distress, where the less socially inadequate one feels, the more social avoidance and distress experienced. Feelings of inadequacy has its roots in weak self-esteem, where self-esteem is a validation of one's value, strength and importance; it is a very important aspect in self-concept [16]. People with greater self-esteem would expect praises and validation from others, and would experience greater self-acceptance. That said, the degree of self-esteem affects an individual's relationships development. Exisiting studies have shown that self-esteem has a significant predicting effect on an individual's wellbeing where the higher the level of self-esteem, the lower the sense of loneliness [27]. Undergraduates who are not socially confident are more afraid of being vulnerable, and therefore would be more cautious in the way they behave, which can easily lead to avoidance and distressed behaviours [28]. Social avoidance and distress, to a large extent, is a form of social anxiety, which its negative affect is closely related to an individual's problematic self-understanding [15], which can easily lead to an individual avoiding social interaction and develop avoidance behavior and experience discomfort in social settings.

\subsection{Analysis of the Mediating Effect of Feelings of Inadequacy}

The current study revealed that there is a significant relationship between life events, social avoidance and distress as well as feelings of inadequacy in impoverished tertiary students. Based on the path model, the prediction score of life events on social avoidance and distress is at 0.04 , and the indirect prediction score of life events on social avoidance and distress through feelings of inadequacy is at 0.23 , which composites $85.19 \%$ of the overall effect. This shows that feelings of inadequacy have a fully mediating effect when it comes to life events' influence on social avoidance and distress. It has always been thought that life events directly lead to the increase in social avoidance and distress [21], however, there is no direct causation between life events on social avoidance and distress. It is through an individual's self-understanding and experiences that life events indirectly influence social avoidance and distress behaviour. Due to the uniqueness of financial conditions and family environment, impoverished students commonly experience feelings of inadequacy, and likely to be more severe. Research conducted by Liu [29] and Chen, Liu, \& Zhou [30] have already proven that the more severe the feelings of inadequacy, the less self-efficacy an individual experience. On the other hand, students with greater self-esteem have a higher sense of self-efficacy. Due to the strong feelings of inadequacy, which in turn affects an individual's self-efficacy, impoverished students tend to look for excuses to avoid social interaction 
which increases social avoidance and distress behaviour. Studies have shown that should an individual better manage negative life events, execute proper self-understanding, they would be able to adopt a more positive coping mechanism and character which in turns lead to the development of an optimistic outlook, better physical wellbeing and therefore achieve more academically [31]. It shows that by simple reducing impoverished students' exposure to negative life events and life stressors, it would not be as effective as helping these students in improving their self-concept, increase self-esteem and self-efficacy, as well as reduce the feelings of inadequacy. By addressing these factors, then can the wellbeing and sociability of these underprivileged students be taken care of.

\section{Conclusion and Countermeasures}

Through the study conducted, it can be concluded that (1) there is a significant positive correlation between life events, social avoidance and distress as well as feelings of inadequacy among impoverished undergraduates; (2) Social Avoidance and Distress can be significantly predicted from life events through the feelings of inadequacy that impoverished students experience. It is therefore possible to decrease the influence of life events on social avoidance and distress by increasing self-esteem levels.

In response to the above results, this paper proposes the following educational recommendations.

(1) We should pay attention to the living conditions of impoverished undergraduates, care about their physical and mental health, and give them adaptive education.

The stress results of impoverished undergraduates' life events are significantly higher than those of ordinary undergraduates. It shows that compared with ordinary students, impoverished students are exposed to more life stress, they feel pressure from family economic difficulties in learning and living, and feel maladjustment in the interpersonal interactions, the school environments and the adaptation of life tasks, so attention and care for impoverished undergraduates should start from alleviating the negative impact of life events on their mental health. For impoverished students, changes in interpersonal communication, learning pressure and lifestyle will cause them to become confused in the process of adapting to the environment, cause them feel insecure. When they see other students enjoying life, they will inevitably associate to the economic poverty of their own families, it may causes serious imbalance of mind. Therefore, schools should strengthen the adaptation education, actively pay attention to the psychology and behavior of impoverished undergraduates, actively carry out effective mental health education guidance and protection work, and reduce the impact of negative life events on them.

(2) Caring about physical and mental health of impoverished undergraduates and giving them social adaptation education.

Impoverished undergraduates, as a special group of college students, bear a heavy pressure of economy, life and study, and their social adaptation is facing more tests.Countermeasures can be listed as followed: (1) Compared with other grades, focusing on the life pressure of the fourth-grade impoverished undergraduates, giving more concern about their thesis defense, finding suitable jobs, repaying the student loans, even the emotional issues of "the graduation season is the break-up season" and so on. (2) In terms of academic issues and career planning, we should pay more attention to female students, non-only children and students with particularly difficult economic needs, provide opportunities for learning method exchanges as much as possible, and strengthen guidance on career planning, guide female students to correctly understand college life and increase the level of self-awareness; (3) Strengthening social adaptation education, cultivating impoverished female students to have an optimistic attitude, enhancing their self-regulation ability and reasonable venting ability when coping with difficulties. Encouraging them to participate in social activities and to fully express their inner thoughts.

(3) Carrying out group counseling plans in impoverished undergraduates about the self-awareness education, interpersonal interaction and interpersonal communication, improving their self-esteem and alleviating the impact of life events on social avoidance and distress.

In this study, although the stress, social avoidance and distress of impoverished undergraduates' life events reached a very significant level $(r=0.233)$, life events did not directly predict their social avoidance and distress, but produced indirect predictive effects through defects. That is, when impoverished students with low levels of self-esteem face life stress events, it is easier for them to avoid social interactions and produce negative coping behaviors. Modern psychology generally believes that having normal interpersonal interactions and good interpersonal relationships plays an important role in the maintenance of physical and mental health. Therefore, colleges should strive to optimize the life and learning environment of college students, reduce the frequency of negative life events, and promote impoverished students to actively deal with negative life through extensive group counseling and special lectures on self-awareness education, interpersonal communication and interpersonal communication. Strengthening the self-esteem experience of impoverished undergraduates, improving their interpersonal skills, improving their psychological quality and sense of self-efficacy, reducing their sense of defects, and promoting their correct attribution of life events, and alleviating the impact of life events on social avoidance and distress.

(4) Improve the self-esteem of impoverished undergraduates.

College teachers should encourage and support impoverished undergraduates to actively participate in social activities, integrate themselves into group life, avoid excessive attention to themselves, and should encourage impoverished undergraduates to concentrate more on their academic tasks to acquire excellent academic performance, professional skills and high self-efficacy so as to gain self-energy and improve self-awareness; organize positive and 
beneficial activities and guide impoverished students to actively participate and exercise their social interaction skills; give career planning education, improve their understanding of self-character, help them analyze professional values and realistic career requirements, clarify career development goals, guide correct attribution to develop core competitiveness and improve self-esteem. Thus, they can reduce disadvantages and achieve an increase in self-esteem.

\section{Acknowledgements}

This study was supported by the Youth Fund Projects of Major Breakthrough Research of Humanities and Social Sciences in Zhejiang Colleges, People's Republic of China (2018QN0057).

Thanks must be given to Pro. Liao Chuanjing who worked in Department of Psychological Education, Wenzhou University, he and his professional team gave us many helpful suggestions, guidance and supports.

\section{Conflict of Interest}

All the authors do not have any possible conflicts of interest.

\section{References}

[1] Duncan, G. J., \& Brooksgunn, J. (2000). Family poverty, welfare reform, and child development. Child Development, 71 (1), 188-196.

[2] Mcloyd, V. C. (1998). Socioeconomic disadvantage and child development. American Psychologist, 53 (2), 185-204.

[3] Zhan, X. H., Zhou, Z., Yang, X., \& Xu, W. W. (2008). The influence of family economic situation on college students' mental health. Chinese Journal of Management in Chinese Medicine, 16 (3), 189-191.

[4] Chen., L. N. (2005). Research on character and the mental health of impoverished undergraduates. Journal of Zhongzhou, (3), 136-138.

[5] Zhang., Y. J., Fang., R. L., \& Miao., X. T. et al. (2005). A survey on the mental health status of 76 new impoverished undergraduates. Chinese General Practice. 8 (9): 736-737.

[6] Xu., J. Wang., L. \& Li., Y. (2012). Influences of life events, coping styles on subjective well-being among impoverished students in higher vocational colleges. Health Psychology. 32 (2): $125-128$.

[7] Garnefski, N., \& Kraaij, V. (2006). Relationships between cognitive emotion regulation strategies and depressive symptoms: a comparative study of five specific samples. Personality \& Individual Differences, 40 (8), 1659-1669.

[8] Hojat, M., Gonnella, J. S., Erdmann, J. B., \& Vogel, W. H. (2003). Medical students' cognitive appraisal of stressful life events as related to personality, physical well-being, and academic performance: a longitudinal study. Personality \& Individual Differences, 35 (1), 219-235.

[9] Feng., Z. Guo., T. B. \& Jing,. J. (2006). The social withdrawal and distress of impoverished students in a medical university. South China Preventive Medicine. 32 (5), 37-38.
[10] Zhang., X. M., Wang., Z. D., \& Liao., C. J. (2016). Research on the influencing depression factors of poor college students' depression. Journal of High Education Management, 10 (2), $119-124$.

[11] Hong., Y. J. (2012). Investigation of life events and mental health of impoverished students in rural middle school: Taking four rural middle school in Wenzhou as an example. Journal of Zhejiang International Study University, (6): 104-109.

[12] Xue., Z. X., Lu., L. \& Liang., Z. Q. (2010). Investigation about the depression of poor college students. Chinese Journal of Health Psychology, 18 (7), 853-854.

[13] Liao., C. J., Han., L., \& Yang., H. Q. et al. (2014). Mental health of staying-at-home children in rural areas under the background of urbanization: from the angle of poverty. Journal of Nanjing agricultural University (Social Science Edition), 14 (2), 21-27.

[14] Bernichon, T., Cook, K. E., \& Brown, J. D. (2003). Seeking self-evaluative feedback: the interactive role of global self-esteem and specific self-views. Journal of Personality \& Social Psychology, 84 (1), 194-204.

[15] Orth, U., \& Luciano, E. C. (2015). Self-esteem, narcissism, and stressful life events: testing for selection and socialization. Journal of Personality \& Social Psychology, 109 (4), 707-21.

[16] Wang., X. D., Wang., X. L., \& Ma., H. (1999). Handbook of Mental Health Rating Scale (Updated Version).Press of Mental Health.

[17] Baron, R. M., \& Kenny, D. A. (1986). The moderator-mediator variable distinction in social psychological research: conceptual, strategic, and statistical considerations. Journal of Personality \& Social Psychology,51 (6), 1173-1182.

[18] Wen., Y. H. (2007). Mental health problems of poverty college students and its countermeasures analysis. Journal of Shangdong Youth Administrative Cadres College, 125 (1): 67-68.

[19] Wang., Y. Z. (2007). Social avoidance and distress and their perception of social support among college students. Journal of School Health, 28 (3), 235-237.

[20] Shen., X. F., \& Dong., C. H. (2004). A survey of normal colleges students' Feelings of Inadequacy. Social Psychology Science, 19 (4), 68-71.

[21] Huang., X. K., Zhang., Z., \& Huang., J. Y. (2013). Research on the relationship between the college students' social avoidance and distress and life events. Journal of Jiamusi Educational college, (6), 339-340.

[22] Guo., X. P., Feng., C., \& Zhang., H. L. (2010). The relationship between life events, resilience and mental health of impoverished college students.Chinese Journal of Health Psychology. 18 (11), 1375-1377.

[23] Situ., Q. M., \& Li., J. B. (2007). Relationship between self-esteem and interaction anxiety. Chinese Journal of Health Psychology, 15 (11), 1005-1006.

[24] Wang., T., Tan., J. \& Li., M. et al. (2009). Relationship of social anxiety with self-esteem and personality in medical university students. Journal of Third Military Medical University, 31 (11), 1095-1097. 
[25] Zhong., Y. J. \& Zhang., J. F. (2011). The mediating effects of fears of evaluation on the relations between self-esteem and social anxiety for college students. Psychological Development and Education, (5): 506-511.

[26] Band, E. B., \& Weisz, J. R. (1988). How to feel better when it feels bad: children's perspectives on coping with everyday stress. Developmental Psychology, 24 (2), 247-253.

[27] Huang., X. B., Shen., L. X., Wang., \& X. L. et al. (2006). Correlation among levels of self-esteem, social anxiety and loneliness in senior vocational school students. Chinese Journal of Clinical Rehabilitation, 10 (46), 61-63.

[28] Liao., X., \& Sun., Y. (2010). The study of the relation between social avoidance and self-confidence on college students. Journal of Cangzhou Teacher's College, 26 (2): 70-75.
[29] Liu., C. F., \& Lu., N. (2007). Relationship between attribution style of senior high school students and feeling of inadequacy and self-efficacy. Journal of preventive medical Information, 23 (1), 42-45.

[30] Chen., M. Q., Liu., F. Y., \& Zhou., Z. H. (2008). Relationship between attribution style, feeling of inadequacy and self-efficacy for ethnic minority college students. Journal of Guizhou Normal University (Natural Science), 26 (4): 33-36.

[31] Zhang., L. J. (1998). Study on the relationship between anxiety and life events of impoverished college students. Journal of Shaanxi Normal University (Social Science), 27 (4), 155-157. 